\title{
Does Stress and Anxiety Contribute to COVID-19?
}

\author{
Majid Taati Moghadam ${ }^{1}$, Sajad Babakhani ${ }^{2}$, Sajad Rajabi (iD ${ }^{3}$, Fatemeh Bagheri Baravati ${ }^{4}$, \\ Mohammadali Raeisi ${ }^{5}$ and Amin Sadeghi Dousari ${ }^{6, *}$ \\ ${ }^{1}$ Department of Microbiology, School of Medicine, Iran University of Medical Sciences, Tehran, Iran \\ ${ }^{2}$ Department of Microbiology, North Tehran Branch, Islamic Azad University, Tehran, Iran \\ ${ }^{3}$ International Campus, Iran University of Medical Sciences, Tehran, Iran \\ ${ }^{4}$ Noncommunicable Diseases Research Center, Bam University of Medical Sciences, Bam, Iran \\ ${ }^{5}$ Department of Neurology, Pastor Hospital, Bam University of Medical Sciences, Bam, Iran \\ ${ }^{6}$ Jiroft University of Medical Sciences, Jiroft, Iran \\ "Corresponding author: Jiroft University of Medical Sciences, Jiroft, Iran. Email: amin_sadeghi22@yahoo.com
}

Received 2020 June 02; Revised 2020 June 10; Accepted 2020 June 13.

Keywords: Anxiety, COVID-19, Pandemic, Stressful Situations

\section{Dear editor,}

Stressful situations often cause a wide range of emotions and behaviors, such as anxiety, disturbed sleep, sadness, irritability, anger, and violence. There is evidence indicating that stress can increase the risk of several health conditions, including infectious diseases (viral, bacterial, and parasitic), childhood cancer, etc. (1-5). It also negatively affects the immune system. So that several studies reported that social stressors are associated with increased inflammatory cytokines, which highlights the central nervous system (CNS) signal to induce behavioral, neurological changes with psychiatric symptoms. Therefore, it can be argued that inflammatory cytokines are a major factor in the pathogenesis of stress, anxiety, depression, and other mental disorders $(6,7)$. Thus, the proliferation of $\mathrm{T}$ cells, which are responsible for cellular immunity and the most important arm of the immune system to fight viruses, is reduced in anxious patients. Moreover, it is well-proved that stress is associated with delayed response to the vaccine as well as exacerbated viral and bacterial pathogens. Stress hormones also disrupt the trafficking of neutrophils, macrophages, antigen-containing cells, natural killer (NK) cells, T and B lymphocytes, and produce the necessary cytokines to produce immune responses (8). As a result of the COVID-19 pandemic, which has infected nearly 6.5 million cases and claimed thousands of lives, people are faced with stressful conditions (9). Many studies have shown that one of the best ways to deal with COVID-19 is to strengthen the immune system; Nevertheless, stress, anxiety, and fear, which have increased since the onset of the pandemic, weaken the immune system, which increases susceptibility to developing various diseases (10).
Increased stress, anxiety, and fear can be attributed to factors such as the high mortality rate of COVID-19, the shortage of medical staff, improper treatments, insufficient medical equipment, and scarcity of food, as well as the ambiguous future of the disease (11). In this critical situation, psychologists play an important role because they take care of people's mental health, so the necessary measures should be provided in an excellent way to reduce people's stress. Therefore, considering that stress and anxiety can weaken the immune system, especially in the elderly, it is recommended that patients with COVID-19 be monitored by psychologists to manage the predisposing factors. During the COVID-19 pandemic, families of patients who suffer from mental fatigue also require psychological support. Providing training on managing psychological problems through national broadcasting also would be useful.

\section{Footnotes}

Authors' Contribution: The core idea of this work came from Majid Taati Moghadam was an advisor in the project. All of the authors were involved in writing the manuscript and approved it.

Conflict of Interests: We declare no conflict of interests. Funding/Support: None declared.

\section{References}

1. Akaltun I, Kara SS, Kara T. The relationship between Toxoplasma gondii IgG antibodies and generalized anxiety disorder and obsessive-compulsive disorder in children and adolescents: a new approach. Nord J Psychiatry. 2018;72(1):57-62. doi: 10.1080/08039488.2017.1385850. [PubMed: 28990850]. 
2. Orefici G, Cardona F, Cox CJ, Cunningham MW. Pediatric autoimmune neuropsychiatric disorders associated with streptococcal infections (PANDAS). Streptococcus pyogenes: Basic Biology to Clinical Manifestations. University of Oklahoma Health Sciences Center; 2016.

3. Phillips AC, Carroll D, Khan N, Moss P. Cytomegalovirus is associated with depression and anxiety in older adults. Brain Behav Immun. 2008;22(1):52-5. doi:10.1016/j.bbi.2007.06.012. [PubMed: 17703915].

4. Papp ZE, Horváth M, Kelemen I, Hutanu A, Dobreanu M. The Relationship between Anxiety and Immunity in Pediatric Oncology Patients.J Interdiscip Med. 2019;4(2):87-93. doi:10.2478/jim-2019-0005.

5. LeResche L, Dworkin SF. The role of stress in inflammatory disease, including periodontal disease: review of concepts and current findings. Periodontol 2000. 2002;30:91-103. doi: 10.1034/j.16000757.2002.03009.x. [PubMed: 12236899].

6. Salim S. Oxidative stress: a potential link between emotional wellbeing and immune response. Curr Opin Pharmacol. 2016;29:70-6. doi: 10.1016/j.coph.2016.06.006. [PubMed: 27400336].

7. Lindsater E, Axelsson E, Salomonsson S, Santoft F, Ejeby K, Ljotsson B, et al. Internet-Based Cognitive Behavioral Therapy for Chronic Stress: A Randomized Controlled Trial. Psychother Psychosom. 2018;87(5):296305. doi: 10.1159/000490742. [PubMed: 30041167].

8. Ray A, Gulati K, Rai N. Stress, Anxiety, and Immunomodulation: A Pharmacological Analysis. Vitam Horm. 2017;103:1-25. doi: 10.1016/bs.vh.2016.09.007. [PubMed: 28061967].

9. WHO. Novel Coronaries (2019-Nov) situation report -77. 2020, [cited 2020 Apr 06]. Available from: https://www.who.int/docs/defaultsource/coronaviruse/situation-reports/20200315-sitrep-77-covid19.pdf?sfvrsn=33daa5cb_6.

10. Wang L, Wang Y, Ye D, Liu Q. Review of the 2019 novel coronavirus (SARS-CoV-2) based on current evidence. Int J Antimicrob Agents. 2020;55(6):105948. doi: 10.1016/j.ijantimicag.2020.105948. [PubMed: 32201353]. [PubMed Central: PMC7156162].

11. Brosschot JF, Geurts SA, Kruizinga I, Radstaak M, Verkuil B, Quirin $\mathrm{M}$, et al. Does unconscious stress play a role in prolonged cardiovascular stress recovery? Stress Health. 2014;30(3):179-87. doi: 10.1002/smi.2590. [PubMed: 25100269]. 